\title{
G. Férard, R. Dybkaer and X. Fuentes-Arderiu: Compendium of terminology and nomenclature of properties in clinical laboratory sciences, recommendations 2016 (Silver Book, 2nd ed.)
}

\author{
International Union of Pure and Applied Chemistry (IUPAC), Chemistry and Human \\ Health Division (VII), Subcommittee on Nomenclature for Properties and Units, and \\ International Federation of Clinical Chemistry and Laboratory Medicine (IFCC), Sci- \\ entific Division (IX), Committee on Nomenclature for Properties and Units. Published \\ by The Royal Society of Chemistry, Cambridge, 2017, Print ISBN: 978-1-78262-107-2, \\ PDF eISBN: 978-1-78262-245-1, EPUB eISBN: 978-1-78262-909-2
}

\author{
David B. Hibbert ${ }^{1}$ \\ Received: 22 May 2017 / Accepted: 15 June 2017/Published online: 12 July 2017 \\ (C) Springer-Verlag GmbH Germany 2017
}

This second edition of the Silver Book comes 20 years after the first edition and has been extensively reworked to cover modern metrological principles and some new techniques that are now used in clinical chemistry. The new text takes into account the latest ISO rules for terminology work [not the PAC (Pure and Applied Chemistry) rules] and, not surprisingly as one of the authors (RD) was the IUPAC representative on the Joint Committee for Guides in Metrology (JCGM) Working Group 2 for many years, the International Vocabulary of Metrology (VIM) [1]. By virtue of its membership of the JCGM, IUPAC is signed up to the VIM, although the Chemistry and Human Health Division is possibly the only part of the organization that has wholeheartedly embraced this standard. A section (4: Fundamental Concepts in Communication of Clinical Laboratory Information) stresses the need for a set of rules for transmission of information (4.1.2), and the whole work consistently applies a systematic approach. The perceived need to create a complete system of terms for the concepts in clinical chemistry has led to correct but sometimes awkward terminology. This raises the question of how much new terminology should be introduced if the existing, but not optimally systematic, terms are well used and known. The use of massic, entitic, kelvic, volumic and aeric correctly and systematically expresses kinds-of-

David B. Hibbert

b.hibbert@unsw.edu.au

1 University of New South Wales, Sydney 2031, NSW, Australia quantity of dimension $\mathrm{M}^{-1}, 1^{-1}, \mathrm{~T}^{-1}, \mathrm{~L}^{-3}$ and $\mathrm{L}^{-2}$ (see 5.4.6 for all denominator kinds of quantity), but I know of few chemists who call density volumic mass, or the Boltzmann constant entitic kelvic energy constant (although to be fair mass density and Boltzmann constant are, respectively, allowed synonyms). Well known, and acknowledged by the Green Book [2], is the clinical chemists preference for the short-form substance concentration for amount-of-substance concentration, rather than the recommended amount concentration. It will be interesting to see what the recommendation becomes if IUPAC succeeds in changing the name of amount of substance to chemical amount. However, the clinical chemists are not beyond improving on present accepted standards. I note the preference to hyphenate, against existing authority, amount-of-substance and kind-of-quantity.

Section 5 is a short treatise on metrology, perhaps wasted on many readers, but which underpins the whole approach of the book. The Silver Book goes much further than the Green Book, perhaps where such a discourse might be expected, and is somewhat at odds with the Green Book, which does not mention kind of quantity at all, being happy to refer to quantity throughout.

Section 6 on the transmission of clinical information revolves around the established NPU format for reporting data as Component-System; kind of property with various specifications [3]. It contains approaches for requesting and reporting and will be particularly useful as a concise aide memoire in clinical teaching.

Section 7 Choice and Use of Kinds-of-property for Different Examination Purposes is an eclectic mix going 
through some fairly obvious quantities (e.g. amount of substance and amount concentration) and then a subsection on thermodynamic quantities followed by optical spectroscopy, centrifugation, electrophoresis, and enzymology. Quite where modern techniques of magnetic resonance, chromatography/mass spectrometry for the -omics, DNA sequencing or immunoassays would be treated I do not know, but their absence gives the book an old-fashioned feel.

About half the book is a list of kinds of quantity arranged in increasing dimension, starting with kinds of quantity of dimension 1 (Section 8) and then progressing to kinds of quantity of dimensions not 1 (Section 9). I have highlighted unusual systematic terms but at least some of the better known terminology is allowed.

I note a serious error in the description of measurement uncertainty (6.10.5), which reads "The positive square root of such a variance is termed standard measurement uncertainty, $u$, and the positive square root of the sum of the variances and possible covariances is termed the combined standard measurement uncertainty, $u_{\mathrm{c}}$ [VIM, concept 2.31]". The VIM reference is the definition of combined standard measurement uncertainty "standard measurement uncertainty that is obtained using the individual standard measurement uncertainties associated with the input quantities in a measurement model". Unfortunately, the method of "obtaining" $u_{\mathrm{c}}$ from individual $u$ is taking the square root of the sum of the variances only in the unlikely case of the measurand being a simple sum of independent input quantities. Covariances are never just added either, the appropriate method being the equation for the so-called propagation of error, which includes the partial differentials of the measurand as functions of each input quantity (see GUM [4], Section 5). I am aware that the IUPAC-reviewing procedure for these recommendations was to send the whole book to the panel of reviewers. Although this is usual practice, at the time this reviewer complained that a book of 209 pages densely packed with important information across a whole sub-discipline of chemistry could not be reviewed like a typical PAC paper covering a narrow topic in perhaps 40 or 50 pages.

Enough of criticism. The Silver Book should be on the shelf of every laboratory, which has anything to do with clinical or biological measurement. Especially fascinating is Section 1, which traces the history of recommendations back to the early 1950s. In this reviewer's opinion, the present Silver Book is a tribute to the work of René Dybkaer who gave a lecture in Danish in 1957 "Standardizing unit symbols in work of the clinicochemical laboratory", and who has continued with his tireless work ever since, now of course being one of the authors of this edition. Read also 5.1.3 which goes back 10000 years to the earliest evidence of humans' appreciation of quantities.

To conclude I give a closing sentence of Section 1 "A history is not complete without a word about the correspondents from many parts of the world, some irate or emotional, others coldly logical." For such an apparently coldly logical book, I am sure the reception of the new edition of the Silver Book will generate at least some amount-of-heat (7.1.1).

\section{References}

1. JCGM 200:2012 International vocabulary of metrology-basic and general concepts and associated terms (VIM). BIPM, Sèvres. www.bipm.org/vim

2. Cohen ER, Cvitas T, Frey JG, Holmstrom B, Kuchitsu K, Marquardt R, Mills I, Pavese F, Quack M, Stohner J, Strauss HL, Tamaki M, Thor A (2007) Quantities, units and symbols in physical chemistry (Green Book). The Royal Society of Chemistry, Cambridge

3. Petersen UM, Dybkær R, Olesen H (2012) Pure Appl Chem $84: 137-165$

4. JCGM 100:2008 Evaluation of measurement data-guide to the expression of uncertainty in measurement (GUM). BIPM, Sèvres. www.bipm.org/en/publications/guides/gum.html 